\title{
ANDRÉS BELLO, EL PROGRESISTA ATERRIZADO
}

\author{
Jorge Edwards
}

\begin{abstract}
Resumen: Andrés Bello fue un portento hoy difícil de imaginar. Inspirador de la Constitución de 1833, redactor del Código Civil, primer rector de la Universidad de Chile, autor de la Gramática de la lengua castellana, poeta y traductor de clásicos de la poesía europea, parece que no hubiera zona de las humanidades o la legislación que no pudiera transformar con su pensamiento nítido, su prosa intachable. Cuando se cumplen 150 años desde su muerte, el escritor Jorge Edwards desempolva su figura firme, sabia y comprensiva y la coloca como guía para los agitados tiempos que corren.
\end{abstract}

Palabras clave: Andrés Bello, Diego Portales, Latinoamérica, gramática, Constitución de 1833.

\section{ANDRÉS BELLO, A DOWN TO EARTH PROGRESSIST}

Abstract: Andres Bello was a prodigy hard to imagine nowdays. Inspirer of the 1833 Constitution, he wrote the Civil Code, was the first chancellor of the University of Chile, author of Gramática de la lengua castellana, poet and translator of classical European poetry. There seemed to be no area of the humanities or the law that he could not transform by his clear thought and impeccable prose. Now, 150 years after his death, writer Jorge Edwards dusts off his firm, wise and understanding figure and turns him into a beacon of inspiration during the troubled times now prevailing.

Keywords: Andrés Bello, Diego Portales, Latin America, grammar, 1833 Constitution.

Jorge Edwards. Escritor chileno. Premio Nacional de Literatura (1999) y Premio Cervantes (1999). Sus libros más recientes son El descubrimiento de la pintura (2013), Los círculos morados (2012) y La muerte de Montaigne (2011). 
J oaquín Edwards Bello, bisnieto de Andrés Bello, cronista, ensayista, autor de ficciones literarias, habló del "bisabuelo de piedra". Lo que ocurría en el Santiago de Chile de la primera mitad del siglo XX era que la estatua de Bello, en su sillón de mármol, en actitud pensativa, frente a la puerta principal de la Universidad de Chile, una de las tantas creaciones suyas, dominaba el centro antiguo de la ciudad. En piedra, en mármol, en efigie, en placas conmemorativas, Bello estaba en todas partes. Era el inspirador de la Constitución Política de 1833, texto conservador que puso fin a largos años de anarquía, el redactor del Código Civil, que sirvió de ejemplo a muchos otros países de Hispanoamérica, el primer rector de la universidad, el organizador y primer oficial mayor del Ministerio de Relaciones Exteriores, el autor de la Gramática de la lengua castellana, el poeta y traductor de clásicos de la poesía europea. Su presencia era tan fuerte, tan constante, tan evidente, que mi generación, marcada por la vanguardia estética de los años veinte, por los intelectuales rupturistas de los treinta y cuarenta, por el existencialismo francés, trató de evitarla, de ignorarla a toda costa. Andrés Bello era una estatua y un nombre de calle. Era tema de disertaciones académicas, de seminarios y cursillos que tenían ecos en toda la región, y sobre todo en su Caracas de origen. Rechazar a don Andrés, a la vasta constelación bellista, era rechazar el oficialismo, el lugar común, la sabiduría obligatoria, impuesta desde el exterior. Por el contrario, entender la enseñanza de Bello ha sido emprender un camino de regreso. El que dio la primera señal fue el crítico uruguayo Emir Rodríguez Monegal en su notable ensayo biográfico El otro Andrés Bello, publicado por primera vez en 1969, en Monte Ávila Editores, Caracas. El otro, es decir, el poeta, el humanista, el filósofo. Describir al Andrés Bello de una visión moderna, nuestra, ha exigido una reflexión de segundo grado, un despojarse de prejuicios, un descubrimiento y un redescubrimiento. Bello fue un incomprendido parcial, un solitario en una época de asonadas y sociedades colectivas, masónicas o no. Pudo, sin embargo, trabajar, pensar, escribir, debido, antes que nada, a una formación superior, adquirida en la Caracas conventual de fines de la Colonia, y porque después encontró, en Inglaterra y sobre todo en su Chile de adopción, apoyos superiores que actuaron a favor suyo por inteligencia y también por intuición, por instinto. No es fácil entender el resorte último, la clave de esta situación. Mi opinión personal, en pocas palabras, es 
que los años de anarquía profunda, de guerras civiles, que siguieron a las luchas de la independencia, produjeron el efecto de una vacuna. El Chile anárquico de los años 20, el de después de la caída del poder de Bernardo O'Higgins en 1823, conoció tales extremos de desorden, de inseguridad, de inestabilidad política, de pérdida de las normas más elementales de convivencia, que la experiencia hizo los efectos de un antídoto moral e intelectual. Chile se transformó en el país del orden, de la moderación, del respeto a la ley: una especie de milagro en su contexto regional.

Andrés Bello desembarcó en Valparaíso con toda su numerosa familia en 1829, contratado por el gobierno, después de haber vivido 19 años en Londres. Había sido llamado por el presidente chileno Francisco Antonio Pinto, liberal, amigo de José María Blanco White y de José Joaquín de Mora, a quienes había conocido o con quienes se había relacionado desde su paso por Londres. Bello sería el profesor de Aníbal Pinto, hijo de Francisco Antonio y a su vez Presidente de la República hacia fines del siglo XIX. Lo interesante, sin embargo, es que la guerra civil que asolaba al Chile de ese momento fue resuelta poco después de la llegada de Bello, a comienzos de 1830, en el decisivo triunfo de los conservadores en la batalla de Lircay. Bello entendió de inmediato que el país donde se instalaba con su mujer inglesa y sus seis hijos tenía una necesidad aguda de estabilidad, de respeto de la ley, de orden público. Sus amistades intelectuales inglesas, que formaban parte del llamado grupo de la Holland House, reformistas moderados, críticos declarados del jacobinismo francés, entre los que figuraba el gran Edmund Burke, fueron para él una fuente de inspiración constante y mantuvo con ellos una nutrida y permanente correspondencia.

El joven Bello, nacido en Caracas en 1781, formó parte en 1810, junto a Simón Bolívar y a Luis López Méndez, de una misión diplomática que viajó a Londres a fin de obtener el reconocimiento de la independencia venezolana por Inglaterra. Los enviados de Caracas tomaron contacto de inmediato con el secretario de relaciones exteriores inglés de la época, el marqués Richard Wellesley. Lo interesante es que Wellesley, precavido, formado en hábitos diplomáticos que todavía no se conocían en América del Sur, recibió a los venezolanos en su domicilio particular y no en el Foreign Office, con la idea de evitar un compromiso prematuro. Después de la invasión napoleónica de la Península, las 
relaciones de Inglaterra con España habían mejorado mucho. Los representantes de los nuevos gobiernos de América del Sur habían pasado a ser personas difíciles para Inglaterra. El propio Francisco de Miranda, el venezolano que los había precedido en su instalación en territorio inglés, había perdido influencia en la prensa inglesa y estaba sometido a una vigilancia policial estricta.

Se supone que Simón Bolívar, que entonces tenía veintisiete años, defendió en la reunión con el secretario Wellesley, en forma ardorosa y no autorizada por las instrucciones de la Junta de Caracas, la idea de la plena independencia política de Venezuela, cosa que forzó su rápido regreso a Caracas. En cambio, la permanencia de Andrés Bello en Londres durante 19 años, con grandes altibajos económicos, con notables encuentros con personajes hispanoamericanos, españoles, ingleses, haciendo toda clase de trabajos esporádicos en la diplomacia venezolana, colombiana, chilena, se conoce en parte y exige de nosotros un esfuerzo de conjetura y de imaginación. Se sabe que se hizo amigo de Miranda, el precursor, y que en cambio tomó distancia con respecto al arrogante, impetuoso, millonario Simón Bolívar. También conoció a José de San Martín, de paso en Londres en 1811, tuvo una estrecha amistad con John Mill, el padre de John Stuart Mill, y su correspondencia privada con José María Blanco White fue abundante y constante por ambas partes.

¿Qué factores influyeron para que Andrés Bello, muy poco después de su llegada a Chile, se transformara en el aliado más seguro, más laborioso, más eficiente de los conservadores? El tema es de gran complejidad y de fascinante interés histórico. Reservado, introvertido, apartado de toda forma de frivolidad, nunca mezclado en la acción política cotidiana, Andrés Bello se convirtió, sin embargo, en el hombre de confianza de Diego Portales, el ministro del Interior del primer Presidente conservador, el general José Joaquín Prieto, triunfador de Lircay. Para algunos de los interesantes ensayistas históricos del Chile del siglo XIX, Prieto pudo aprovechar la fuerza de su ministro Portales y la inteligencia humanista de Bello porque era "el menos militar de los militares de su tiempo". Por otro lado, la alianza de Portales y Bello tiene un aspecto enigmático. A primera vista, parecen personajes enteramente contrapuestos. Portales era comerciante, dueño de un estanco poderoso, desconfiado, autoritario, poco aficionado a los símbolos del poder. 
$\mathrm{Su}$ correspondencia es criolla en el lenguaje, chispeante, insolente, divertida. El hombre abandonaba con relativa frecuencia los despachos ministeriales para irse al otro lado del río Mapocho, a las "chinganas" del barrio popular y mal afamado de La Chimba. Cuando lo requerían para tareas urgentes de gobierno, solían irlo a buscar a esos lugares de vida alegre. El ministro no se tomaba demasiado en serio, no amaba en absoluto las liturgias y ceremonias del Estado, pero se hacía cargo de los temas difíciles con decisión, con autoridad, con lucidez extraordinaria. Sabía, por lo tanto, que la presencia de Bello era indispensable y le daba siempre, sin vacilar, un apoyo completo.

Hubo un punto de desacuerdo importante entre ambos personajes, y el ministro Portales, empeñado a fondo en el tema, no le quitó su apoyo al humanista silencioso. Fue el asunto de la guerra contra la Confederación Perú-Boliviana. Ambos países se habían unido bajo el mando del mariscal Andrés Santa Cruz, personaje mestizo, de gran astucia, de extraordinario carisma, de visiones ambiciosas. Portales pensó desde el primer momento que la Confederación era una fuerza peligrosa, hostil, en la vecindad de la república chilena en formación, y se propuso, con toda claridad, sin la menor vacilación, destruirla. El punto de vista de Bello, como es de imaginar, fue prudente, pacifista, partidario de buscar soluciones negociadas. Diego Portales impuso su criterio y mandó una expedición marítima al mando del almirante Manuel Blanco Encalada, que había alcanzado a intervenir en las luchas de la Independencia. El general triunfador en Yungay, en el interior de la sierra del Perú, fue Manuel Bulnes, quien asumiría poco después el segundo período presidencial chileno, de acuerdo con la Constitución de 1833, que fijaba períodos de cinco años de duración y con la posibilidad de una reelección, los primeros decenios, cuyos plazos se cumplían en forma rigurosa. Al conocer en su destierro de Boulogne-sur-Mer, en el norte de Francia, las noticias del traspaso de poderes entre Prieto y Bulnes, efectuado en forma enteramente pacífica en 1841, el general argentino José de San Martín escribió que Chile era "el único país que sabía ser república hablando en español”. Cita la carta de San Martín en sus Recuerdos literarios, publicados por primera vez en $1878 \mathrm{y}$ donde el ataque a las ideas de Andrés Bello es uno de los temas centrales, José Victorino Lastarria. Bello había sido profesor de Lastarria en la década de los treinta y la 
relación respetuosa entre ambos se mantuvo, a pesar de las diferencias ideológicas, durante toda la vida.

En los abundantes ensayos, estudios, biografías de Andrés Bello se intenta pocas veces mostrarlo en su unidad de pensamiento, en su extraordinaria coherencia intelectual. En una notable biografía reciente, Andrés Bello: la pasión por el orden ${ }^{1}$, el profesor chileno Iván Jaksic se empeña en explicar este carácter unitario de la obra de Bello y llega lejos en su análisis. Se plantea en forma interesante, necesaria, la relación entre el Andrés Bello poeta, gramático, estudioso de la literatura de la lengua desde sus orígenes medievales, filósofo, hasta el Bello jurista y legislador. Como ya dije, la estrecha confianza entre hombres tan diferentes como Bello y Portales es un enigma histórico. Ahora pienso que el salvaje asesinato del ministro Portales por un ínfimo grupo de amotinados militares, en 1837, produjo el efecto contrario al que buscaban sus autores: una admiración popular del ministro asesinado y un fortalecimiento del Estado de Derecho que él había estado creando en fiel sintonía con Bello.

En sus primeros pasos en la diplomacia sudamericana en Inglaterra, Bello encontró tiempo para escribir poemas y para estudiar los orígenes de la lengua española. Su examen detenido, minucioso, del Cantar de Mío Cid, lo llevó a conocer a fondo el paso del latín al español de los primeros tiempos. Bello era un lector eximio de Virgilio, de Horacio, de Cicerón, de Séneca. Ahora bien, esas lecturas habían sido paralelas con el estudio de los primeros juristas romanos. En sus discusiones sobre los programas de derecho de la Universidad de Chile, insiste en forma brillante en la conveniencia de incluir buenos estudios de derecho romano. Bello conoce el derecho romano desde sus orígenes republicanos y también conoce su influjo en el derecho español, que se manifiesta con claridad, a su juicio, en Las siete partidas. Pues bien, su lectura atenta del Cantar de Mío Cid lo lleva a la conclusión de que el "Cantar tercero", donde se narra la afrenta inferida por los Infantes de Carrión a las hijas del Cid y se describe la corte convocada por el rey Alfonso VI (Alfonso El Castellano) a pedido del Cid para hacer justicia, tiene una relación directa con los principios romanos del derecho y con los procedimientos jurídicos que se aplican en España.

${ }^{1}$ Iván Jaksic, Andrés Bello: la pasión por el orden (Santiago: Editorial Universitaria, 2001). 
En otras palabras, Andrés Bello ve una relación inspiradora para él, importante para su noción de lo que deberían ser las repúblicas hispanoamericanas, entre la lengua de los orígenes y el derecho de los orígenes: el latín, el español, el derecho romano y el de la Edad Media española. Él hizo sus estudios en la Caracas ilustrada de fines de la época colonia, alcanzó a ser funcionario de la administración colonial, y pensó que una solución razonable para las nuevas naciones independientes sería una monarquía constitucional. Más tarde, frente a un vacío político, desarrolló el concepto de repúblicas independientes estables, donde el respeto de la ley, elevado a una categoría casi religiosa, era una clave de los nuevos sistemas. Se ha sugerido a menudo que los presidentes chilenos del siglo XIX, hasta el estallido de la Revolución de 1891, eran monarcas a plazo fijo. Es una verdad a medias, puesto que uno de los desarrollos políticos principales de ese siglo de estabilidad interna es el de un sistema electoral gradualmente más amplio, de mayor participación, que culmina en el siglo XX con el voto femenino y el voto secreto. En seguida, la sucesión presidencial se practica en forma estricta. Lo que provoca el conflicto armado de 1891, una lucha entre un Congreso conservador y un poder ejecutivo liberal, es en forma determinante la intervención electoral que practicaban los presidentes para imponer a sus sucesores, deformación crecente del sistema que Bello y Portales habían imaginado.

La preocupación central de Andrés Bello, su objetivo último, fue impedir que la independencia de las colonias hispanoamericanas, con su inevitable fragmentación, con la creación de numerosos Estados nacionales, se tradujera en una pérdida del idioma común y en una situación general de anarquía. Mantener el idioma era el primer desafío cultural de ese mundo separado de la Península. Crear repúblicas estables, viables, inspiradas en el derecho romano y en los derechos nacionales de la Europa moderna, era un proceso paralelo al de la defensa de la continuidad lingüística. En una etapa determinada, el racionalismo de Bello, miembro en Londres de la curiosa logia de los Caballeros Racionales, lo condujo a proponer algunas modificaciones de la ortografía castellana con la idea de suprimir algunas arbitrariedades: cambiar la "y" griega por "i" latina, suprimir las haches mudas, usar la jota en lugar de la "g" sorda, proponer el uso de la " $k$ " en lugar de la "ca", etcétera. Fueron usos que tuvieron una momentánea difusión en la América de 
lengua española y que el propio Bello, al cabo de largos años y en una segunda revisión del problema, fue de los primeros en abandonar.

La Gramática de la lengua castellana, publicada en Chile en 1847, fue uno de los proyectos más ambiciosos de unificación de las reglas del idioma y a la vez de independencia cultural. Bello consideraba que la gramática de la Real Academia Española adolecía de una excesiva dependencia del latín, hasta el punto de seguirlo en la conjugación de los verbos y en la declinación de los sustantivos. Había que hacer una gramática del castellano real, vigente, "desembarazado de ciertas tradiciones latinas que de ninguna manera le cuadran".

En su prefacio, tiene un párrafo que se ha citado muchas veces:

No tengo la pretensión de escribir para los castellanos. Mis lecciones se dirigen a mis hermanos, los habitantes de HispanoAmérica. Juzgo importante la conservación de la lengua de nuestros padres en su posible pureza, como un medio providencial de comunicación y un vínculo de fraternidad entre las varias naciones de origen español derramadas sobre los dos continentes.

Era siempre una noción de progreso efectivo, no teórico, alejado de toda forma de jacobinismo. Sus enemigos locales, encabezados por su alumno José Victorino Lastarria, fueron siempre majaderos, repetidores de consignas, profundamente áridos. El lenguaje de uno de ellos, José Miguel Infante, es de un simplismo, de una barbarie, de una flagrante incorrección, y nunca falta el ataque a Bello como "extranjero" en Chile.

En Introducción a los estudios gramaticales de Andrés Bello, escrito un siglo después por Amado Alonso, gran gramático, filólogo y crítico literario español, sostuvo que la de Bello era "la mejor gramática que tenemos de lengua española". Desde luego, no soy experto en la materia, pero creo que las explicaciones de Andrés Bello sobre el verbo en castellano son de las más claras, las más incisivas y brillantes que se hayan escrito en nuestra lengua. Un escritor moderno de cualquiera de las regiones de la lengua española, de la meseta castellana o de los confines australes de la Patagonia, puede leer esas páginas y entender aspectos del verbo y de sus funciones que antes no había entendido del todo. En otras palabras, Bello es uno de nuestros grandes clásicos, y a pesar de la muy abundante bibliografía que ha suscitado desde mediados del siglo XIX, es uno de nuestros grandes desconocidos. 
Se trataba de fijar la lengua, de darle normas válidas en sus vastísimos dominios, de defender la identidad cultural de las nuevos Estados, sin romper la tradición intelectual hispánica con sus orígenes latinos. Entre el Mester de Juglaría medieval y la poesía de los primeros poetas del Nuevo Mundo, la del poeta soldado español Alonso de Ercilla y la de su rival chileno, nacido en Angol de los Confines, Pedro de Oña, Bello encontraba una continuidad asombrosa. El estudio mayor, más apasionado y a la vez más atento, permitía descubrir vasos comunicantes extraordinarios. Andrés Bello, en medio de sus tareas agotadoras, pudo escribir una Silva a la agricultura de la zona tórrida, evocación de la naturaleza de su Venezuela natal, y una hermosa traducción de Victor Hugo, La oración por todos, donde resuenan ecos de la mejor poesía de la lengua.

El trabajo de preparación del Código Civil chileno, que le llevó años de minuciosa y escrupulosa dedicación, tuvo un propósito último parecido: dar seguridad al trabajo y a la propiedad, establecer bases sólidas de convivencia, crear un sistema jurídico eficaz, razonable, moderno para su época. Andrés Bello ya era senador, ciudadano chileno por gracia, rector de la Universidad de Chile. La década de 1840, encabezada por un Presidente de la República jurista, juez de profesión, Manuel Montt, terminaría definida en biografías de Bello como la "década triunfal". El venezolano nacionalizado chileno, siempre nostálgico de su juventud en Caracas, no dejó nunca de asistir a las sesiones de la comisión codificadora, que él presidía, y fue al final el autor casi único de ese código que entró en vigencia el primero de enero de 1857. Hay, sin embargo, un detalle digno de destacarse: Manuel Montt, como Presidente en ejercicio de la República y después como ex Presidente que había reanudado sus tareas en la Corte Suprema de Justicia, asistía con puntualidad a casi todas las sesiones. Había un antecedente que se conocía bien en el lejano Chile: Napoleón Bonaparte asistía con extraordinaria constancia a las sesiones de codificación del derecho civil francés, modelo aproximado del código chileno. Uso el término "aproximado" con precisión e intención, puesto que Bello cotejaba siempre la legislación española y nunca abandonaba sus conocimientos del derecho romano y de la legislación inglesa. El código huyó de la influencia francesa jacobina, revolucionaria, cuya crítica ya había conocido Bello de primera mano en su frecuentación de los pensadores políticos ingleses 
de la Holland House. El conocimiento del derecho romano de los tiempos de la república, completado con el estudio de Las siete partidas, permitieron que escapara de un modelo único. Su texto se adaptó a las condiciones de las nuevas sociedades hispanoamericanas con justeza, con realismo, con pensamiento original. Fue una legislación de progreso, que terminó con el mayorazgo, que mejoró la situación jurídica de los hijos nacidos fuera del matrimonio, que facilitó la circulación comercial de los bienes. Bello supo distanciarse del pesimismo radical de Simón Bolívar, que había "arado en el mar", según su propio balance personal, y del autoritarismo cerrado de Diego Portales, que no creía que una legislación bien hecha bastara para imponer el orden social, que sostenía que el orden social sólo se mantenía en Chile por "el peso de la noche". Andrés Bello inventó una legislación republicana posible, equilibrada, convincente, y obtuvo resultados extraordinarios. Su redacción clara, su conocimiento estético y gramatical del idioma, permitieron que su construcción legal fuera comprendida y aceptada por la gran mayoría de los chilenos e imitada después en una parte importante de Hispanoamérica. Andrés Bello fue un legislador prudente, cuya enorme erudición se había transformado en sabiduría, que desconfiaba de las novedades antes de analizarlas a fondo, en todos sus matices y en sus consecuencias. Su Código Civil ha sido modificado muchas veces, pero según algunos especialistas actuales, rige todavía en alrededor de setenta por ciento de su articulado. Su personalidad, estudiada hasta en sus menores detalles y relativamente desconocida en los tiempos actuales, alcanzó una síntesis única: poeta, estudioso del idioma y de su literatura, gramático, legislador, educador, político en el sentido amplio de la palabra, más allá del corto plazo.

Murió en Santiago en octubre de 1865, poco antes de cumplir los ochenta y cuatro años de edad, y sus honras fúnebres fueron uno de los sucesos más notables del siglo XIX chileno. No está demás apuntar que su médico de cabecera fue el doctor Guillermo Blest, irlandés de origen y padre del precursor de la novela chilena moderna, Alberto Blest Gana. Tres o cuatro días antes de su fallecimiento, después de examinarlo en forma detenida, dijo que ya sólo había que esperar y dejarlo descansar. Hay otro detalle interesante: el ex presidente Manuel Bulnes, que había gobernado en el segundo de los decenios del Chile conservador (1841-1851), el triunfador de la guerra contra la Confederación Perú- 
Boliviana, asistió a la casa del difunto acompañado de su hijo Gonzalo, quien después se convertiría en un clásico de la historiografía chilena y recordaría la escena fúnebre con emoción y con detalles notables. Agrego elementos del entierro del ex senador de la república y ex rector de la Universidad de Chile, que tomo de la notable biografía de Iván Jaksic. Hubo una reacción colectiva, espontánea, enorme para esa época, de alrededor de diez mil personas. En el trayecto de la Catedral de Santiago al Cementerio General, un grupo de estudiantes apartó los caballos que debían llevar la carroza fúnebre y arrastró la carroza con sogas. El desfile era seguido por las principales personas de gobierno, de la universidad, de los sectores intelectuales, por los miles de voluntarios que habían concurrido y por un destacamento de caballería. Ignacio Domeyko, importante hombre de ciencias de origen polaco que también había sido contratado por el gobierno y que sucedió a Bello en el Consejo Universitario, fue uno de los oradores principales, acompañado por importantes actores políticos, entre ellos Federico Errázuriz Zañartu, ministro de Instrucción Pública y que llegó a ser algunos años más tarde Presidente de la República.

Es una historia antigua, pasada, y tiene, sin embargo, una vigencia extraordinaria. No creo que perdamos nada con recordarla. Quizá, en los tiempos confusos y relativamente bárbaros que corren, sea una evocación saludable y hasta necesaria. El sectarismo de muchas regiones de la América Latina de hoy, que suele ir acompañado de altos niveles de ingenuidad y de ignorancia, tendría mucho que aprender del ejemplo de don Andrés. La vastedad de su erudición, de su visión de humanista, de su trabajo legislativo, constituye un contraste con la situación de estos días y una enseñanza extraordinaria para todos nosotros. Andrés Bello perteneció a una especie humana escasa de hispanoamericanos tranquilos, reflexivos, de sabiduría superior. El hecho de que Chile lo haya adoptado, le haya dado su nacionalidad y haya tenido un respeto profundo por su trabajo, a pesar de las ardientes polémicas que despertaba, merece una reflexión de las generaciones actuales. Fue un hombre de progreso, de conocimientos clásicos y modernos, poeta y hombre de ciencias, además de constitucionalista, civilista, internacionalista. El amor por el mundo sudamericano, por su naturaleza, por sus formas de convivencia; su esfuerzo por mantener una identidad propia, nueva en su tiempo, también son esenciales para definirlo. Los que lo acusaron 
con virulencia, con expresiones de odio, aprovechando para hacerlo las libertades públicas que él mismo había contribuido a instalar en el Chile del siglo XIX, cometen un error parecido al de muchos exaltados de hoy. Es una historia que se repite. Pero todo indica que Bello es un contemporáneo nuestro, un maestro y a la vez un compañero de ruta.

Madrid, marzo de 2015. EP 